\title{
The STEM Educational Framework Applied to "The Properties of Matter" by Using Real-life Activities: Providing Inspiration to Grade 2 Lower Secondary Students at Nongbuadaeng Secondary School to Grow Technical Skills and to Acquire a Life-long Scientific Attitude toward Problem Solving.
}

\author{
Sriwai Kanhathaisong and Giorgio Morettini \\ Nongbuadaeng Secondary School Office of Basic Education Area 30 Chaiyaphum 36210 Thailand
}

\begin{abstract}
The objectives of this study were 1) to develop a set of STEM activities to inspire students to grow technical skills and a scientific attitude toward problem solving, whose effectiveness was established with the $80 / 80$ criterion, 2) to compare pre-test and post-test, using statistical analysis, to assess the effectiveness of the STEM activities and 3) to evaluate, with a likert scale, students' feeling after using the set of STEM activities. The study was performed over the first semester of the 2018 academic year at the Nongbuadeang Secondary school in Thailand. The sample consisted of 39 students from grade 2 lower secondary school, (ISCED level 2). Three tools had been used during the research: The set of 5 STEM activities, two 30 questions 4 choices tests and a likert scale questionnaire to evaluate students' feeling toward the activities. Statistical analysis computations -such as average, standard deviation, percentiles and the t-test at the 0.05 significance level- have been used to measure the quality of the set of STEM activities. The results are as follow: 1) the standard of performance produced a 86.20/84.73 therefore higher than the $80 / 80$ criterion, 2) the post-test result are better than the pre-test; the former shows an average of 28.35 over 30 and the t-test at 0.05 level confirms a significant difference between averages and 3 ) the student's feeling likert scale questionnaire reported an average of 4.60 over 5.00 maximum score.
\end{abstract}

Keywords: $21^{\text {st }}$-century; E1/E2-standard; likert-scale; multiple-choice; questionnaire 